\title{
InterCriteria Analysis for selection of specific growth rate models of batch cultivation by Saccharomyces cerevisiae yeast for ethanol production
}

\author{
Mitko Petrov \\ Department of Bioinformatics and Mathematical Modelling \\ Institute of Biophysics and Biomedical Engineering, Bulgarian Academy of Sciences \\ 105 Acad. George Bonchev St., Sofia, Bulgaria \\ e-mail: mpetrov@biomed.bas.bg
}

Received: 15 April 2019

Revised: 2 May 2019

Accepted: 6 May 2019

\begin{abstract}
In this study we have developed an application of a new method for multicriteria decision analysis namely InterCriteria Analysis (ICA). The method is based on the apparatus of the index matrices and the intuitionistic fuzzy sets. The ICA has been used to evaluate and select specific growth rate models for cultivation by the Saccharomyces cerevisiae yeast. Different unstructured models Monod, Mink, Tessier, Moser, Aiba, Andrews, Haldane, Luong, Edward, and Han-Levenspiel have been considered in order to explain the cell growth kinetics. The application of the ICA for the specific growth rate of glucose has shown that there are many correlation connections between the investigated models. The models have been reduced only to Monod and Mink. Each of the two models can be used for modelling.
\end{abstract}

Keywords: Saccharomyces cerevisiae, Intuitionistic fuzzy sets, InterCriteria Analysis, Growth rate models, Index matrix, Intuitionistic fuzzy pairs.

2010 Mathematics Subject Classification: 03E72, 93A30.

\section{Introduction}

The ethanol is the most important organic compound which has a wide application in different industry fields: food, perfumery-cosmetic, chemical, millwright, etc. In recent years enormous attention is paid to the ethanol production as a fuel. Ethanol production from 
renewable resources can improve energy security, reduce accumulation of carbon dioxide, and decrease urban air pollution. When blended with gasoline, "neat" ethanol reduces the release of smog forming compounds. Thus, ethanol from lignocellulosic materials holds great promise as a new industry in the world and has the potential for making a significant contribution to the solution of major energy as well as environmental problems [31].

The multicriteria decision support method, bearing the specific name InterCiteria Decision Analysis method [10] is based on two mathematical concepts - intuitionistic fuzzy sets (IFSs) [1, 2, 5, 8] and index matrices (IMs) [3, 4, 6, 7, 9]. The approach employs the concept of index matrices (IMs), making particular use of some of the operations introduced over them, as well as the concept of intuitionistic fuzzy sets fuzziness, giving us the tools to construct the IMs of intuitionistic fuzzy pairs [11], defining the presence or absence of dependency/correlation between any pair of criteria within the set.

Until now, ICA has found successful application in economics [12, 13] for structural and parametric identification of bioprocesses [20, 24, 25, 27, 28], as well as selection of the most appropriate growth rate model for the cultivation of the Kluyweromyces strain marxianus var. lactis MC 5 [26], and so on. [21, 22].

In this study ten unstructured models have been examined Monod, Mink, Tessier, Moser, Aiba, Andrews, Haldane, Luong, Edward, and Han-Levenspiel by 11 criteria. Variables have been included for removing of the uncertainty in the parametric identification restrictions of the basic kinetic process. After that we have applied ICA method for selection of a specific growth rate model at batch cultivation by Saccharomyces cerevisiae yeast.

\section{Kinetic model of the fed-batch and batch processes}

The mathematical model of the process is based on the mass balance equations by perfect mixing in bioreactor. The batch model for Saccharomyces cerevisiae yeast is obtained at feed flow rate $F=0$ [19]:

$$
\begin{gathered}
\frac{d X}{d t}=\rho(S) X \\
\frac{d S}{d t}=-\frac{1}{Y_{S / X}} \rho(S) X \\
\frac{d E}{d t}=\frac{1}{Y_{S / E}} \rho(S) X
\end{gathered}
$$

where: $X$ - cell concentration, g/l; $S$ - glucose concentration, g/l; E- ethanol concentration, g/l; $t$ - time, $\mathrm{h} ; \rho(S)$ - specific growth rate from glucose, $\mathrm{h}^{-1} ; \mathrm{Y}_{\mathrm{S} / \mathrm{X}}$ and $\mathrm{Y}_{\mathrm{S} / \mathrm{E}}$ - yield coefficients, $\mathrm{g} / \mathrm{g}$. The initial conditions of models (1)-(3) are: $X(0)=0.27 \mathrm{~g} / \mathrm{l} ; S(0)=31.30 \mathrm{~g} / \mathrm{l} ; E(0)=0.47 \mathrm{~g} / \mathrm{l}$.

\subsection{Specific growth rate models}

The models for the growth rate of glucose $\rho(S)$ rate is unknown, so the work investigates ten unstructured models: $\mathrm{M}_{1}-$ Monod, $\mathrm{M}_{2}-$ Mink, $\mathrm{M}_{3}-$ Tessier, $\mathrm{M}_{4}-$ Moser, $\mathrm{M}_{5}-$ Aiba, $\mathrm{M}_{6}-$ 
Andrews, $\mathrm{M}_{7}-$ Haldane, $\mathrm{M}_{8}-$ Luong, $\mathrm{M}_{9}-$ Edward, and $\mathrm{M}_{10}-$ Han-Levenspiel $[16,17,23$, 29, 30]. The models are shown in Table 1.

\begin{tabular}{ccccc}
\hline \hline Model & Equation & Model & Equation \\
\hline $\mathrm{M}_{1}$ & $\rho(S)=\frac{\rho_{m} S}{K_{S}+S}$ & $\mathrm{M}_{6}$ & $\rho(S)=\frac{\rho_{m} S}{\left(K_{S}+S\right)\left(1+S / K_{S I}\right)}$ \\
$\mathrm{M}_{2}$ & $\rho(S)=\frac{\rho_{m} S^{2}}{K_{S}+S^{2}}$ & $\mathrm{M}_{7}$ & $\rho(S)=\frac{\rho_{m} S}{K_{S}+S+S^{2} / K_{S I}}$ \\
$\mathrm{M}_{3}$ & $\rho(S)=\rho_{m}\left(1-\exp \left(-S / K_{S I}\right)\right)$ & $\mathrm{M}_{8}$ & $\rho(S)=\frac{\rho_{m} S}{K_{S}+S}\left(1-S / S_{m}\right)^{n}$ \\
$\mathrm{M}_{4}$ & $\rho(S)=\frac{\rho_{m} S^{\alpha}}{K_{S}+S^{\alpha}, \alpha>0}$ & $\mathrm{M}_{9}$ & $\rho(S)=\frac{\rho_{m} S}{K_{S}+S+(1+S / K)\left(S^{2} / K_{S I}\right)}$ \\
$\mathrm{M}_{5}$ & $\rho(S)=\frac{\rho_{m} S}{K_{S}+S} \exp \left(-S / K_{S I}\right)$ & $\mathrm{M}_{10}$ & $\rho(S)=\frac{\rho_{m} S\left(1-S / S_{m}\right)^{n}}{S+K_{S}\left(1-S / S_{m}\right)^{m}}$ \\
\hline
\end{tabular}

Table 1. Investigated specific growth rate models dependent on glucose

The denotations in Table 1 are as follows: $\rho_{m}$ - maximum growth rate, $\mathrm{h}^{-1} ; K_{S}-$ Monod saturation constants for cell growth on glucose, g/l; $\alpha$ - Moser constant; $K_{S I}-$ inhibition constants for cell growth on glucose, g/l; $K$ - constant in Edward model, g/l; $S_{m}$ - critical inhibitor concentrations, above which the reactions stops, $\mathrm{g} / \mathrm{g} ; m, n$-constants in the Luong and the Han-Levenspiel models.

All denominators in the models $\mathrm{M}_{1}-\mathrm{M}_{10}$ are different and larger than zero, for example $\left(K_{S}+S\right)>0$, etc.

\subsection{Criteria of evaluation of the model parameters}

The mathematical estimation of the model parameters is based on the minimization of some quantities that can be calculated and the estimation of a function of parameters. If the model under consideration is linear, the estimation is generally an easy task. However, there is no general theory for nonlinear parameter estimations. The least-squares error is commonly employed as a criterion to inspect how close the computed profiles of the state variables come to the experimental observations [32]:

$$
\min _{\mathbf{x}} J=\sum_{j=1}^{N}\left(\frac{\left[X_{e}\left(t_{j}\right)-X_{m}\left(t_{j}\right)\right]^{2}}{X_{e \max }^{2}}+\frac{\left[S_{e}\left(t_{j}\right)-S_{m}\left(t_{j}\right)\right]^{2}}{S_{e \max }^{2}}+\frac{\left[E_{e}\left(t_{j}\right)-E_{m}\left(t_{j}\right)\right]^{2}}{E_{e \max }^{2}}\right)
$$

where $J$ - criteria for minimization; $\mathbf{x}$ - vector of estimated parameters in specific growth rate models, $\mathbf{x}=\left[\mu_{m}, K_{S}, K_{S I}, \ldots, Y_{S / X}, Y_{S / E}\right]^{\mathrm{T}} ; N$ - number of experiment, $X_{e}\left(t_{j}\right), S_{e}\left(t_{j}\right), E_{e}\left(t_{j}\right)-$ experimental data, $X_{m}\left(t_{j}\right), S_{m}\left(t_{j}\right), E_{m}\left(t_{j}\right)$ - simulation data; $X_{e \max }, S_{e \max }, E_{e \max }-$ maximal values of biomass, glucose and ethanol; $t_{j}$ - time partitions, $\mathrm{h}$. 


\subsection{Criteria for model validation}

The best dependences are defined by criteria of minimization: $C_{1}=\min _{\mathbf{x}} J \times 10^{-3}$. The statistical criteria: $C_{2}$ - statistic $\lambda$, relative error $\left(S_{L}\right)$ of the kinetics variables $(X, S$, and $E)-$ $C_{3}=S_{L}^{X} \times 10^{-2}, C_{4}=S_{L}^{S} \times 10^{-2}$, and $C_{5}=S_{L}^{E} \times 10^{-2}$. Fisher coefficient $F(N-2, Q)$ of the kinetics variables $-C_{6}=F_{X}, C_{7}=F_{S}$, and $C_{8}=F_{E}$, for degree of freedom $(N-2, Q)$. For criteria $C_{2}$, tabular Fisher coefficient $\mathrm{F}^{\lambda}(Q, N-2)$, are computing for degree of freedom $(Q, N-2)$.

Experimental correlation coefficient $R^{2}$ for kinetics variables: $C_{9}=R_{X}^{2}, C_{10}=R_{S}^{2}$, and $C_{11}=R_{E}^{2}$ for degree of freedom $N-2$. For number of the experiments $N=12$, and number of the kinetics variables $Q=3$. Full formulas of statistical criteria are presented in [26].

We have developed an algorithm and a program on Compaq Visual FORTRAN 90 to determine the parameters in the models and the computing criteria. For solving the nonlinear problem (4) we have used BCPOL with double precision from IMSL Library of COMPAQ Visual FORTAN 90 [15].

\section{Results and discussion}

\subsection{Results after modelling of the processes}

The index matrix $\mathbf{A}$ for different specific growth rate models $\left(\mathrm{M}_{1}-\mathrm{M}_{10}\right)$ and criteria $\left(C_{1}-C_{11}\right)$ is shown in Table 2.

\begin{tabular}{cccccccccccc}
\hline \hline $\mathbf{A} \equiv$ & $\boldsymbol{C}_{\mathbf{1}}$ & $\boldsymbol{C}_{\mathbf{2}}$ & $\boldsymbol{C}_{\mathbf{3}}$ & $\boldsymbol{C}_{\mathbf{4}}$ & $\boldsymbol{C}_{\mathbf{5}}$ & $\boldsymbol{C}_{\mathbf{6}}$ & $\boldsymbol{C}_{\mathbf{7}}$ & $\boldsymbol{C}_{\mathbf{8}}$ & $\boldsymbol{C}_{\mathbf{9}}$ & $\boldsymbol{C}_{\mathbf{1 0}}$ & $\boldsymbol{C}_{\mathbf{1 1}}$ \\
\hline \hline $\mathbf{M}_{\mathbf{1}}$ & 0.646 & 188.674 & 0.880 & 2.251 & 25.362 & 1.001 & 1.002 & 1.028 & 1.000 & 1.000 & 0.998 \\
$\mathbf{M}_{\mathbf{2}}$ & 0.618 & 137.734 & 1.450 & 30.710 & 24.037 & 1.001 & 1.005 & 1.023 & 1.000 & 1.000 & 0.998 \\
$\mathbf{M}_{\mathbf{3}}$ & 0.559 & 135.609 & 0.855 & 11.243 & 24.332 & 1.001 & 1.001 & 1.025 & 1.000 & 1.000 & 0.998 \\
$\mathbf{M}_{\mathbf{4}}$ & 3.129 & 146.528 & 4.707 & 45.471 & 22.569 & 1.011 & 1.087 & 1.011 & 0.998 & 0.998 & 0.996 \\
$\mathbf{M}_{\mathbf{5}}$ & 0.581 & 138.659 & 2.772 & 6.992 & 22.441 & 1.004 & 1.014 & 1.018 & 1.000 & 1.000 & 0.998 \\
$\mathbf{M}_{\mathbf{6}}$ & 0.600 & 149.377 & 0.620 & 5.486 & 24.845 & 1.000 & 1.002 & 1.026 & 1.000 & 1.000 & 0.998 \\
$\mathbf{M}_{\mathbf{7}}$ & 0.609 & 156.714 & 0.626 & 4.349 & 24.941 & 1.000 & 1.002 & 1.026 & 1.000 & 1.000 & 0.998 \\
$\mathbf{M}_{\mathbf{8}}$ & 0.558 & 136.228 & 0.906 & 9.524 & 24.179 & 1.001 & 1.002 & 1.024 & 1.000 & 1.000 & 0.998 \\
$\mathbf{M}_{\mathbf{9}}$ & 0.614 & 158.768 & 0.717 & 4.715 & 25.012 & 1.000 & 1.001 & 1.027 & 1.000 & 1.000 & 0.998 \\
$\mathbf{M}_{\mathbf{1 0}}$ & 0.529 & 135.204 & 1.763 & 14.544 & 23.213 & 1.002 & 1.002 & 1.022 & 1.000 & 1.000 & 0.998 \\
\hline \hline
\end{tabular}

Table 2. Index matrix A

Now, let us see the index matrix A. The criteria of evaluation of the model parameters $\left(C_{1}\right)$ is changed in the interval $C_{1} \in[0.529,3.129]$. The relative errors for the kinetic variables is changed in the interval $C_{3}, C_{4}, C_{5} \in[0.620,45.471]$. The criteria $C_{2}$ and $C_{6}$ to $C_{11}$ are statistical. 
They are used for the model validation. Their experimental values are changed in the intervals: $C_{2} \in[135.204,188.674], C_{6}, C_{7}, C_{8} \in[1.000,1.087]$, and $C_{9}, C_{10}, C_{11} \in[0.996$, 1.000].

The theoretical values of $C_{2}$ and $C_{6}$ to $C_{11}$ are given from statistical tables [32]. Fisher coefficient for $C_{2}$ is $F^{\lambda}(3,10)=3.71$. For Fisher coefficients $\left(C_{6}-C_{8}\right), F(10,3)=8.79$, and for correlation coefficients $\left(C_{9}-C_{11}\right)$ the tabular value is $R^{2}(10)=0.576$. The $C_{2}>F^{\lambda}(3,10)$ the experimental Fisher coefficients $\left(C_{6}-C_{8}\right)<F^{\lambda}(3,10)$, and the experimental correlation coefficients $\left(C_{9}-C_{11}\right)>R(10)$. The results show that in terms of the criteria for validation $\left(C_{2}, C_{6}-C_{11}\right)$ all specific growth rate models are adequate.

The experimental and simulated results of the ten models for the specific grown rate of Saccharomyces cerevisiae are shown from Figure 1 to Figure 3.

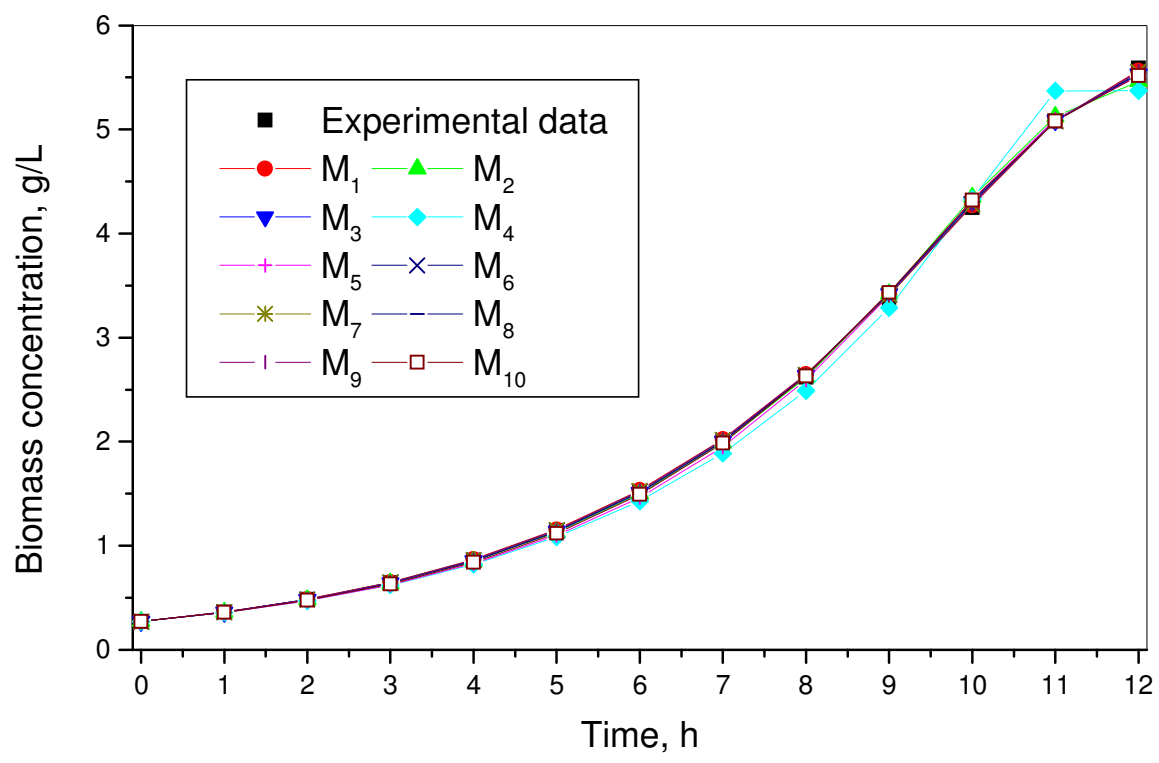

Figure 1. Biomass concentration

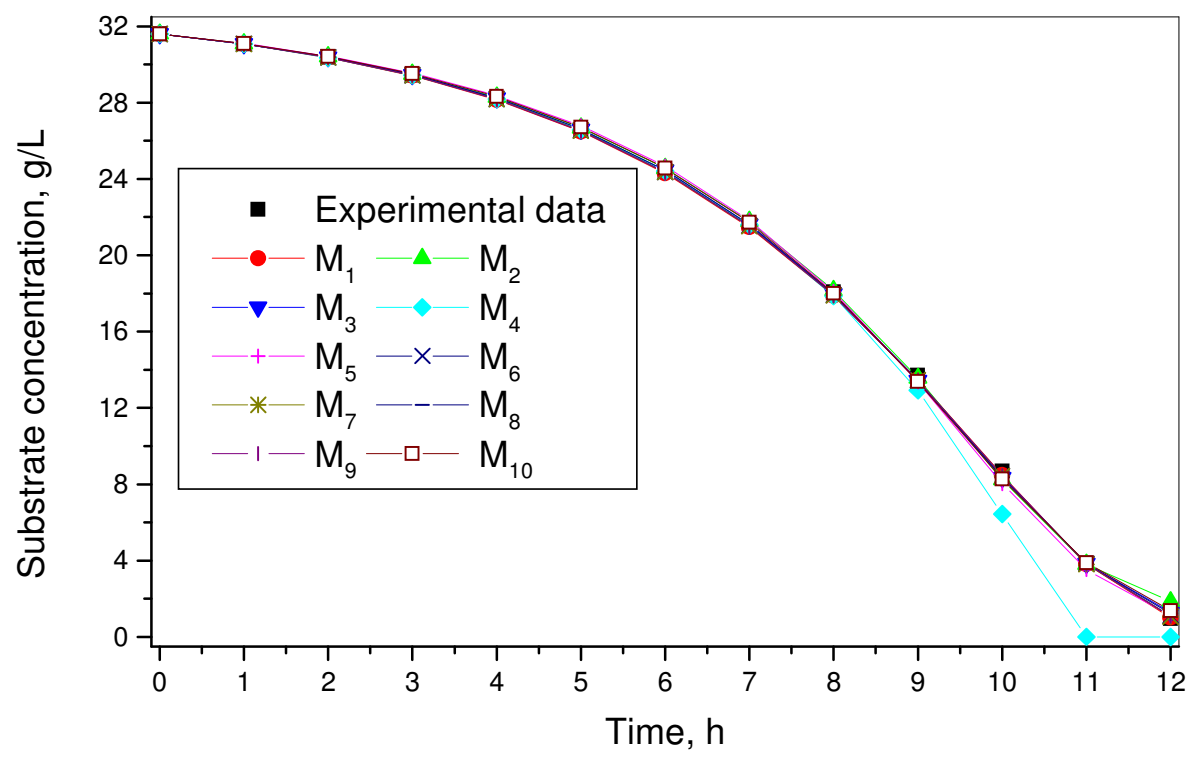

Figure 2. Substrate concentration 


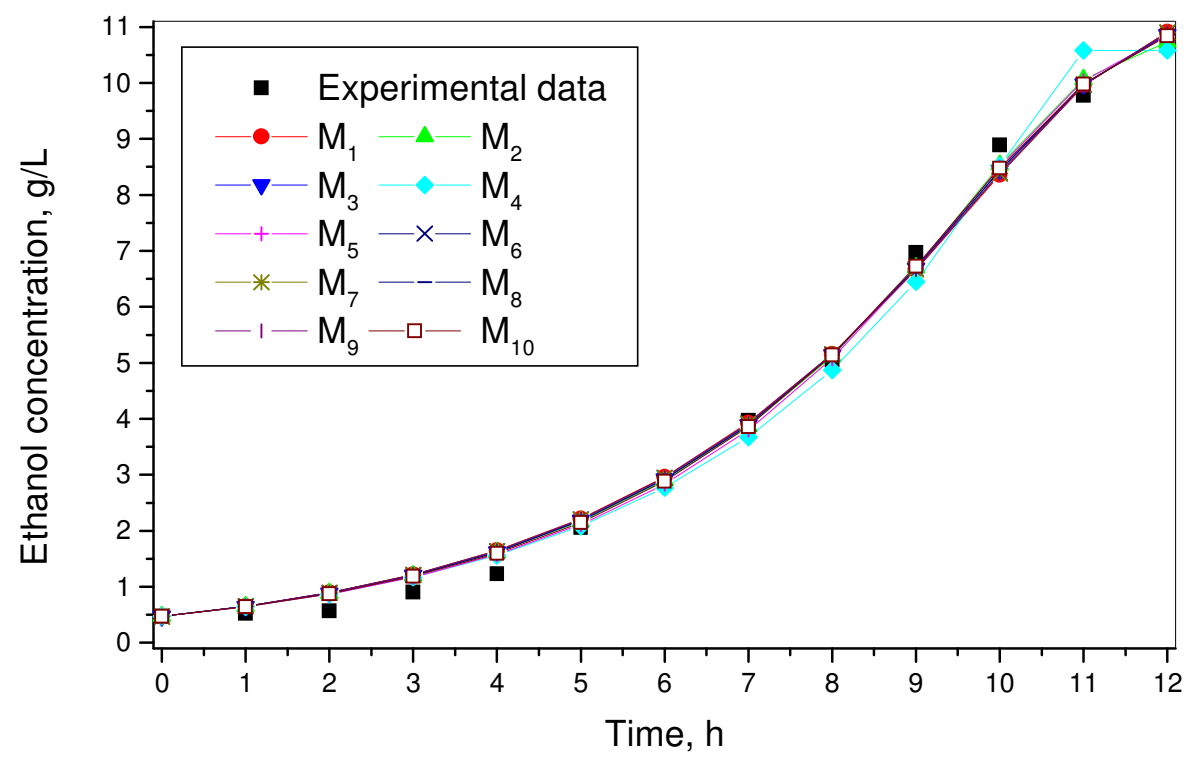

Figure 3. Ethanol concentration

Figure 1 to Figure 3 with different specific growth rate models present a very good match between experimental and simulated results. It should be mentioned that $\mathrm{M}_{4}$ model has a worse result for all kinetics variables in comparison to the rest of the models and it should be dropped out of the research.

\subsection{Applications of ICA for selection of the specific growth rate models}

For the sake of clarity, we will show the rules for determining the positive consonance, the negative consonance and the dissonance between the criteria. Atanassova et al. [14] have discussed an important aspect of the ICA approach related to the possibilities for defining the intuitionistic fuzzy threshold values that help discriminate between the positive consonance, the negative consonance and the dissonance between the criteria (Figure 4).

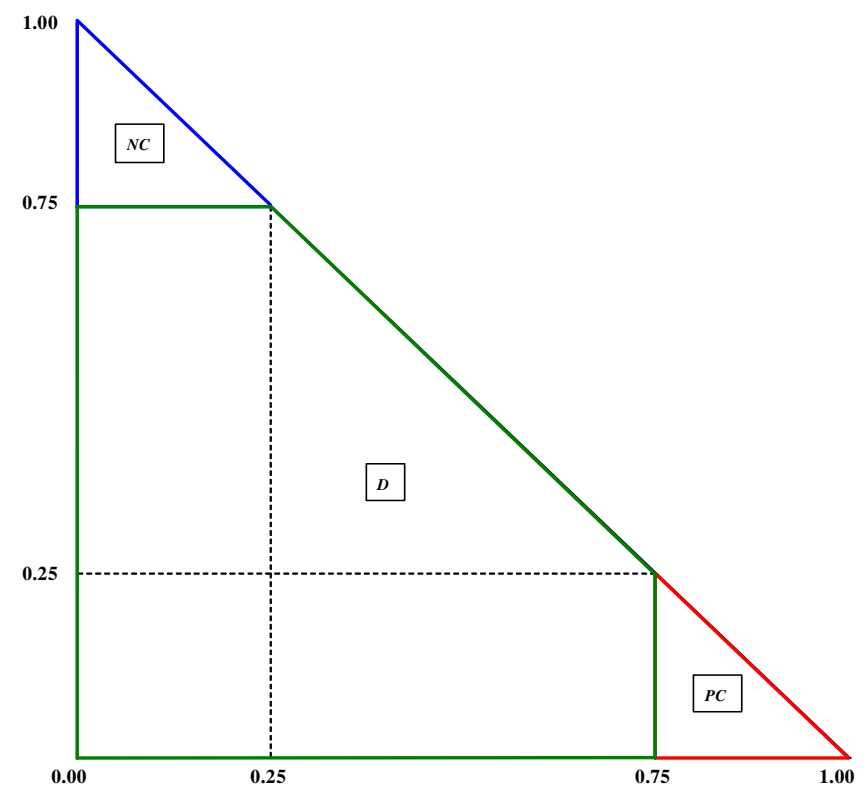

Figure 4. The triangle of positive consonance, negative consonance and dissonance 
The triangular zone for the negative consonance $(N C)$ from Figure 4 corresponds to where the pairs of the criteria which exhibit $N C$ will be located. Formally, this area can be expressed as:

$$
\mathrm{NC}=\{\langle\mu, v\rangle \mid \mu \in[0.00,0.25] \& \nu \in[0.75,1.00] \&(\mu+v) \leq 1\}
$$

The triangular zone for positive consonance $(P C)$ from Figure 4 corresponds to where the pairs of criteria which exhibit $P C$ will be located. Formally, this area can be expressed as:

$$
P C=\{\langle\mu, v\rangle \mid \mu \in[0.75,1.00] \& v \in[0.00,0.25] \&(\mu+v) \leq 1\}
$$

The pentagonal zone for dissonance $(D)$ from Figure 4 corresponds to the place where the pairs of criteria which are in $D$ will be located. Formally, this area can be expressed as:

$$
\mathrm{D}=\{\langle\mu, v\rangle \mid \mu \in[0.00,0.75] \& v \in[0.00,0.75] \&(\mu+v) \leq 1\}
$$

For selecting growth rate models we have to have many high values of the membership function $(\mu)$ because we have accepted $\alpha=0.95$ and $\beta=0.05$ in this study. The method is used for selection of growth rate models from lactose and oxygen.

The values of membership function $(\mu)$ and non-membership function $(v)$ have been calculated with the help of the software developed by our colleagues for the realization of the method [18].

For determination of the positive consonance, negative consonance and dissonance the following threshold values have been assumed $(\alpha, \beta)=[0.95,0.05]$.

The index matrix for membership function $(\mu)$ of different specific growth rate models is shown in Table 3.

\begin{tabular}{rcccccccccc}
\hline \hline & $\mathbf{M}_{\mathbf{1}}$ & $\mathbf{M}_{\mathbf{2}}$ & $\mathbf{M}_{\mathbf{3}}$ & $\mathbf{M}_{\mathbf{4}}$ & $\mathbf{M}_{\mathbf{5}}$ & $\mathbf{M}_{\mathbf{6}}$ & $\mathbf{M}_{\mathbf{7}}$ & $\mathbf{M}_{\mathbf{8}}$ & $\mathbf{M}_{\mathbf{9}}$ & $\mathbf{M}_{\mathbf{1 0}}$ \\
\hline \hline $\mathbf{M}_{1}$ & & 0.764 & $\mathbf{0 . 9 8 2}$ & 0.909 & 0.727 & $\mathbf{1 . 0 0 0}$ & $\mathbf{0 . 9 6 4}$ & 0.945 & $\mathbf{1 . 0 0 0}$ & 0.909 \\
$\mathbf{M}_{2}$ & 0.764 & & 0.745 & 0.673 & $\mathbf{0 . 9 6 4}$ & 0.764 & 0.727 & 0.709 & 0.764 & 0.855 \\
$\mathbf{M}_{3}$ & $\mathbf{0 . 9 8 2}$ & 0.745 & & 0.927 & 0.709 & $\mathbf{0 . 9 8 2}$ & 0.945 & 0.927 & $\mathbf{0 . 9 8 2}$ & 0.891 \\
$\mathbf{M}_{4}$ & 0.909 & 0.673 & 0.927 & & 0.636 & 0.909 & 0.945 & 0.927 & 0.909 & 0.818 \\
$\mathbf{M}_{5}$ & 0.727 & $\mathbf{0 . 9 6 4}$ & 0.709 & 0.636 & & 0.727 & 0.691 & 0.673 & 0.727 & 0.818 \\
$\mathbf{M}_{6}$ & $\mathbf{1 . 0 0 0}$ & 0.764 & 0.982 & 0.909 & 0.727 & & $\mathbf{0 . 9 6 4}$ & 0.945 & $\mathbf{1 . 0 0 0}$ & 0.909 \\
$\mathbf{M}_{7}$ & $\mathbf{0 . 9 6 4}$ & 0.727 & 0.945 & 0.945 & 0.691 & $\mathbf{0 . 9 6 4}$ & & $\mathbf{0 . 9 8 2}$ & $\mathbf{0 . 9 6 4}$ & 0.873 \\
$\mathbf{M}_{8}$ & 0.945 & 0.709 & 0.927 & 0.927 & 0.673 & 0.945 & $\mathbf{0 . 9 8 2}$ & & 0.945 & 0.855 \\
$\mathbf{M}_{9}$ & $\mathbf{1 . 0 0 0}$ & 0.764 & $\mathbf{0 . 9 8 2}$ & 0.909 & 0.727 & $\mathbf{1 . 0 0 0}$ & $\mathbf{0 . 9 6 4}$ & 0.945 & & 0.909 \\
$\mathbf{M}_{\mathbf{1 0}}$ & 0.909 & 0.855 & 0.891 & 0.818 & 0.818 & 0.909 & 0.873 & 0.855 & 0.909 & \\
\hline \hline
\end{tabular}

Table 3. Index matrix for membership function of different specific growth rate models

The interpretations of the intuitionistic fuzzy triangle for the different models in the real boundaries of $\mu$ and $v$ is shown in Figure 5a. For the sake of clarity, Figure 5b shows the change of $\mu$ and $v$ in their actual intervals $\mu \in[0.6,1.0]$ and $v \in[0.0,0.4]$. 


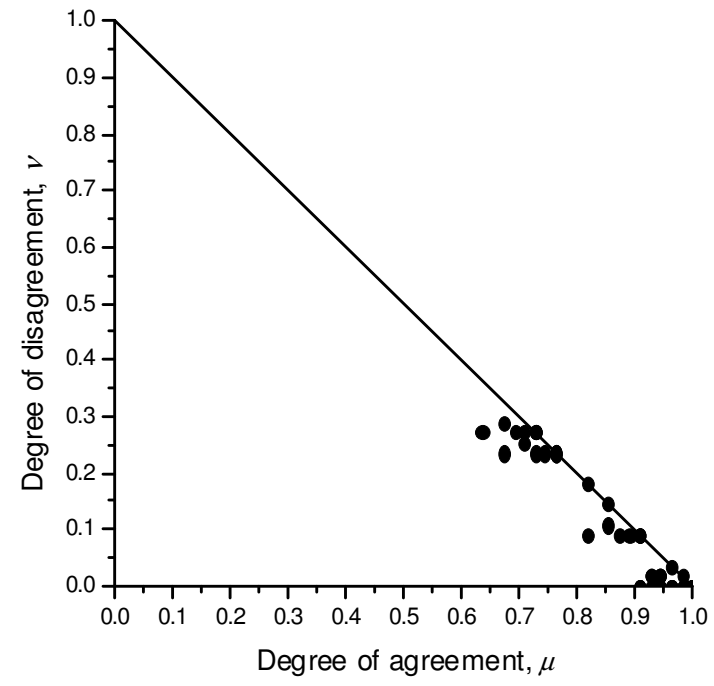

a) without zoom

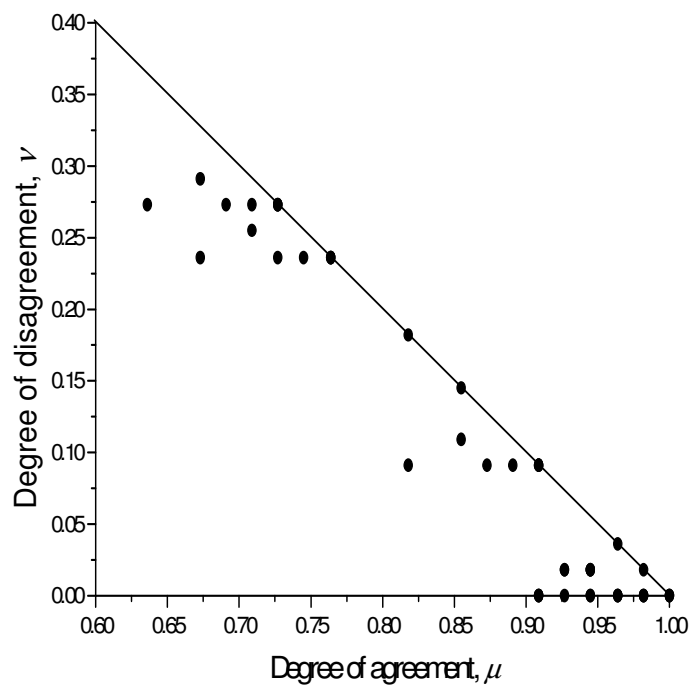

b) with zoom

Figure 5. The intuitionistic fuzzy triangle for the investigated specific growth models

When selecting a suitable model, we basically start using the model with less complexity (fewer parameters to be identified).

Now let us look at Table 3 and Figure 4. The positive consonance you have:

- The first group of models: $\mathrm{M}_{1}-\mathrm{M}_{3}-\mathrm{M}_{6}-\mathrm{M}_{7}-\mathrm{M}_{9}$, we have a very strong $(\mu=$ $0.982)$, strict $(\mu=1.0)$, and strong $(\mu=0.964)$ positive consonance. Therefore, $\mathrm{M}_{3}$, $\mathrm{M}_{6}, \mathrm{M}_{7}$ and $\mathrm{M}_{9}$ models are dropped out in the process modelling. We choose the $\mathrm{M}_{1}$ model (Monod), which has the simplest description.

- For the second group of models: $\mathrm{M}_{2}-\mathrm{M}_{5}$, we have a strong $(\mu=0.964)$ positive consonance. We choose $\mathrm{M}_{2}$ (Mink). The $\mathrm{M}_{5}$ model drops out.

The following groups of patterns are repeated with the first group $\left(\mathrm{M}_{3}-\mathrm{M}_{6}-\mathrm{M}_{9}\right)$ and $\left(\mathrm{M}_{6}-\mathrm{M}_{7}-\mathrm{M}_{9}\right)$.

The $\mathbf{M}_{8}$ has a model connection $\left(\mathbf{M}_{7}-\mathbf{M}_{8}-\mathbf{M}_{9}\right)$. However, $\mathbf{M}_{7}$ and $\mathbf{M}_{9}$ models are dropped out of the first group. Hence, model $\mathrm{M}_{8}$ is also dropping from the research.

Models $\mathrm{M}_{4}$ and $\mathrm{M}_{10}$ have dissonance with all others and therefore fall out. This is also shown in Figure 1 to Figure 3.

All other combinations of models where we have dissonance are not included in the study.

The application of the ICA has shown that we have a very high degree of agreement between the tested models. Of all ten models there are only two Monod and Minik.

\section{Conclusions}

The application of the InterCriteria Analysis for determination of the correlation connections between the specific growth rates has shown that eight models can be eliminated from all ten 
initial models. Only the models of Monod and Mink have remained. In the end, we choose the Monod model for a specific growth rate of batch process for cultivation of Saccharomyces cerevisiae yeast.

The application of ICA for establishment of correlation connection between different models for the specific growth rate proved to be very useful. In this way using of ICA for a negative consonance was not correctly chosen (they do not reflect the real situation) and for this aim we have to search another description of the process.

\section{References}

[1] Atanassov, K. (1983). Intuitionistic fuzzy sets, Proceedings of VII ITKR's Session, Sofia (Deposed in Central Science-Technical Library of Bulgarian Academy of Sciences 1697/84) (in Bulgarian)

[2] Atanassov, K. (1986). Intuitionistic fuzzy sets, Fuzzy Sets and Systems, 20 (1), 87-96.

[3] Atanassov, K. (1987). Generalized index matrices, Comptes rendus de l'Academie Bulgare des Sciences, 11 (40), 15-18.

[4] Atanassov, K. (1991). Generalized Nets, World Scientific, Singapore.

[5] Atanassov, K. (1999). Intuitionistic Fuzzy Sets: Theory and Applications, PhysicaVerlag, Heidelberg.

[6] Atanassov, K. (2010a). On index matrices, Part 1: Standard Sases, Advanced Studies in Contemporary Mathematics, vol. 20, no. 2, pp. 291-302.

[7] Atanassov, K. (2010b). On index matrices, Part 2: Intuitionistic Fuzzy Case, Proceedings of the Jangjeon Mathematical Society, vol. 13, no. 2, pp. 121-126.

[8] Atanassov, K. (2012). On Intuitionistic Fuzzy Sets Theory, Springer, Berlin.

[9] Atanassov, K. (2014). Index Matrices: Towards an Augmented Matrix Calculus, Springer, Cham.

[10] Atanassov, K., Mavrov, D., \& Atanassova, V. (2014). Intercriteria decision making: a new approach for multicriteria decision making, based on index matrices and intuitionistic fuzzy sets, Issues in Intuitionistic Fuzzy Sets and Generalized Nets, 11, 1-8.

[11] Atanassov, K., Szmidt, E., \& Kacprzyk, J. (2013). On Intuitionistic fuzzy pairs, Notes on Intuitionistic Fuzzy Sets, 19 (1), 1-13.

[12] Atanassova, V., Doukovska, L., Atanassov K., \& Mavrov D. (2014). Intercriteria decision making approach to EU member states competitiveness analysis, Proceedings of 4th International Symposium on Business Modeling and Software Design, Luxembourg, Grand Duchy of Luxembourg, 289-294.

[13] Atanassova, V., Doukovska, L., Mavrov, D., \& Atanassov, K. (2014). Intercriteria decision making approach to EU member states competitiveness analysis: temporal and 
threshold analysis, Proceedings of 7th IEEE International Conference Intelligent Systems IS'2014, Warsaw, Poland, Vol. 1, 97-106.

[14] Atanassova, V., Mavrov, D., Doukovska, L., \& Atanassov, K. (2014). Discussion on the threshold values in the InterCriteria decision making approach, Notes on Intuitionistic Fuzzy Sets, 20 (2), 94-99.

[15] COMPAQ Visual FORTRAN Programmer's Guide, v. 6.6 (2001). Compaq Computer Corporation, Houston, Texas.

[16] Gera, N., Uppaluri, R. V. S., Sen, S. \& Venkata Dasuc, V. (2008). Growth kinetics and production of glucose oxidase using Aspergillusniger NRRL326, Chem. Biochem. Eng. Q., 22 (3), 315-320.

[17] Giridhar, R. \& Srivastava, A. (2002). Model based constant feed fed-batch L-Sorbose production process for improvement in L-Sorbose productivity, Chem. Biochem. Eng. Q., 14 (4), 133-140.

[18] Ikonomov, N., Vassilev, P., \& Roeva, O. (2018). ICrAData - software for intercriteria analysis, Int. J. Bioautomation, 22 (1), 1-10.

[19] Ilkova T., \& Petrov, M. (2010). Nonlinear model predictive control of biotechnological process for ethanol production, J. of Int. Scientific Publications: Materials, Methods \& Technology, 4 (2), 284-297.

[20] Ilkova, T., \& Petrov, M. (2015a). Intercriteria analysis for identification of Escherichia coli fed-batch mathematical model, J. of Int. Scientific Publications: Materials, Methods \& Technology, 9, 598-608.

[21] Ilkova, T., \& Petrov, M. (2015b). Using intercriteria analysis for assessment of the pollution indexes of the Struma river, Advances in Intelligent System and Computing, Vol. 401, 351-364.

[22] Ilkova, T., \& Petrov, M. (2015c). Application of intercriteria analysis to the Mesta river pollution modelling, Notes on Intuitionistic Fuzzy Sets, 21 (2), 118-125.

[23] Kim, D.-J., Choi, J.-W., Choi, N.-C., Mahendran, B., \& Lee, C.-E. (2005). Modeling of growth kinetics for pseudomonas spp. during benzene degradation, Appl. Microbiol. Biotechnol., 69, 456-462.

[24] Pencheva, T., Angelova, M., Atanassova, V., \& Roeva, O. (2015). Intercriteria analysis of genetic algorithm parameters in parameter identification, Notes on Intuitionistic Fuzzy Sets, 21 (2), 99-110.

[25] Pencheva, T., Angelova, M., Vassilev, P., \& Roeva, O. (2016). Intercriteria analysis approach to parameter identification of a fermentation process model, Advances in Intelligent Systems and Computing, Vol. 401, 385-397.

[26] Petrov, M., \& Ilkova, T. (2016). Intercriteria decision analysis for choice of growth rate models of batch cultivation by strain Kluyveromyces marxianus var. lactis MC 5, J. of Int. Scientific Publications: Materials, Methods \& Technology, Vol. 10, 468-486. 
[27] Roeva, O., Fidanova, S., Vassilev, P., \& Gepner, P. (2015). Intercriteria analysis of a model parameters identification using genetic algorithm, Proceedings of the 2015 Federated Conference on Computer Science and Information Systems, 501-506.

[28] Roeva, O., Vassilev, P., Angelova, M., \& Pencheva, T. (2015). Intercriteria analysis of parameters relations in fermentation processes models, Lecture Notes in Computer Science, 9330, 171-181.

[29] Saravanan, P., Pakshirajan, K., \& Saha, P. (2011). Kinetics of phenol degradation and growth of predominant Pseudomonas species in a simple batch stirred tank reactor, Bulgarian Chemical Communications, 43 (4), 502-509.

[30] Sudipta, D., \& Mukherjee, S. (2010). Performance and kinetic evaluation of phenol biodegradation by mixed microbial culture in a batch reactor, Int. J. of Water Resources and Environmental Engineering, 2 (33), 40-49.

[31] Viesturs, U., Simeonov, I., Pencheva, T., Vanags, J., Petrov, M., Pavlov, Y., Roeva, O., Ilkova, T., Vishkins, M \& Hristozov, I. (2010). Contemporary Approaches to Modelling, Optimisation and Control of Biotechnological Processes (Ed. Stoyan Tzonkov), Professor M. Drinov Academic Publishing House, Sofia, Bulgaria.

[32] Vuchkov, I., \& Stoyanov, S. (1986). Mathematical Modelling and Optimisation of Technological Objects, Technique, Sofia (in Bulgarian) 